\title{
On names, pronouns, and spelling
}

Contrary to anthropological custom, most people appear in this book either with their real names or with their established pen names. As writers, they have an expressed desire to be recognised and known in that capacity. Passages where we speak about the lives of authors or quote unpublished texts by them while mentioning their names have been discussed and revised in agreement with them. Whenever we have not been able to reach the people we write about, or when mentioning them by name might have caused them embarrassment or problems, we refer to them with initials. These pseudonyms may or may not refer to their real initials.

This book has two authors. Some chapters are co-authored, while some are not. 'We' refers throughout the book to Samuli Schielke and Mukhtar Saad Shehata. In co-authored chapters, both authors appear individually in the third person as Mukhtar and Samuli. In single-authored chapters, 'I' refers to Samuli Schielke.

Colloquial Egyptian Arabic and most forms of written Arabic (there are some recent exceptions) use the male gender in pronouns, verbs, and nouns for both men and women. We have not changed this in citations and translations. Since there is no difference between masculine and feminine plural in English, some of the systematically male-gendered structure of collective terms in Arabic (such as masculine plural kuttab for feminine plural katibat, 'writers') is lost in translation.

There are many ways to represent Arabic in Latin letters: those that are standardised are not commonly used by Arabic speakers, while those that are commonly used by Arabic speakers are not standardised. In this book, we use a simplified version of the IJMES rules for Arabic transcription whenever applicable. For names of people, we use the Latinised spellings that are used by individuals themselves. Names of places are spelled following common use in Egypt. This results in some inevitable inconsistency, such as the determinate article $\mathrm{u}$ that is usually spelled El in Egypt, but al- in IJMES transcription, and the vowels ${ }_{9}$ and s that are usually spelled $o$ and e in Egypt, but $u$ and i in IJMES transcription. Passages of Arabic poetry are reproduced in Arabic as they are originally spelled by their authors, not in Latinised transcription. 